\title{
A PRODUÇÃO DOS SABERES DOCENTES E O ESTÁGIO SUPERVISIONADO: O QUE DIZEM AS NARRATIVAS DOS ALUNOS
}

\author{
Edinaldo Medeiros Carmo \\ Winne Katharine Souza Rocha \\ Universidade Estadual do Sudoeste da Bahia \\ (UESB), Vitória da Conquista, Bahia, Brasil
}

\begin{abstract}
Resumo: Esta investigação teve como foco os saberes produzidos pelos licenciados em Ciências Biológicas durante o estágio supervisionado. Ao utilizar como fonte de dados os relatórios de estágio, esta pesquisa examinou as contribuições das disciplinas da Prática de Ensino para a construção dos saberes docentes, sem desconsiderar as dificuldades encontradas pelos estagiários. Os resultados apontam para o fato de que a inserção do licenciado em situações reais de ensino no espaço escolar permite a retradução dos conhecimentos adquiridos na formação inicial. Portanto, as atividades do estágio contribuem para o desenvolvimento profissional dos estudantes de licenciatura, pois Ihes permitem vivenciar, apoiados em reflexões advindas da sua formação, as suas primeiras tentativas de construção dos saberes docentes em contextos de ensino.

PalavRAS-ChaVE: Estágio supervisionado. Formação de professores. Prática de Ensino. Saberes docentes.
\end{abstract}

INTRODUÇÃO

Nas últimas décadas, o desenvolvimento profissional do professor tem assumido o centro de debates ao aparecer articulado com a melhoria da qualidade do ensino e da aprendizagem (GABARDO; HOBOLD, 2011). Desse modo, a ação docente tornou-se alvo de pesquisas que consideram o pro- 
fessor como sujeito crítico, criativo e pesquisador de suas práticas (FRANCO, 2008). Às discussões sobre a formação, incorporam-se, pois, novas abordagens, como"[...] epistemologia da prática, professor reflexivo, prática reflexiva, professor-pesquisador, saberes docentes, conhecimentos e competências [...]" (ALVES, 2007, p. 265).

Essas abordagens têm destacado o papel do professor no processo de ensino, valorizando os seus conhecimentos, a sua história, ou seja, reconhecendo os seus saberes. Nessa perspectiva, as investigações em educação com foco no professor e no exercício docente vêm se desenvolvendo significativamente. Existem relevantes resultados de pesquisas sobre a profissionalização, o percurso profissional, a ação e o pensamento do professor que destacam os seus conhecimentos e a sua condição de "produtor de saberes" (CAMPOS; DINIZ, 2001), isto é, que demonstram a importância e a amplitude da ação docente. Cabe então considerar a heterogeneidade do saber docente, que inspira essas pesquisas, levantada por Tardif (2006). O autor afirma que o saber dos professores é essencialmente heterogêneo, uma vez que é" [....] plural, formado de diversos saberes provenientes das instituições de formação, da formação profissional, dos currículos e da prática cotidiana [...]" (TARDIF, 2006, p. 54).

No contexto da Prática de Ensino, ao realizar o estágio supervisionado, o estudante se insere no universo escolar, iniciando um movimento de reconhecimento profissional e, além disso, um processo de constituição de identidade docente. Nessa atividade inicial, ele se aventura em descobertas, desafios, frustrações e conquistas que o constituirão profissionalmente. No entanto, o estágio supervisionado não envolve apenas a atuação do futuro professor na escola, mas também, e antes disso, as aulas ministradas pelo formador universitário, que, por meio de subsídios teóricos refletidos contextualmente, auxilia no planejamento das intervenções pedagógicas a serem realizadas na escola.

Nesse sentido, o estágio assume de fato o papel formativo que the cabe, que é o de proporcionar um aprendizado em que o estagiário é orientado pelo professor formador e pelo professor da escola, a elaborar um plano de trabalho consistente, considerando as dimensões educacionais da escola e as reais necessidades de aprendizagem dos alunos. É importante considerar a afirmação de Vilela $(2009$, p. 91) ao destacar que "O contato dos professores em formação com a escola básica, supervisionados por um professor universitário, pode ser compreendido como um rico espaço de integração entre dimensões acadêmicas e profissionais da formação". 
Na verdade, a Prática de Ensino possui uma abordagem teórica e prática que tem como objetivo proporcionar aos licenciandos experiências pedagógicas no contexto escolar. Segundo Fagundes e Paz (2012, p. 1), “[...] na prática de ensino, procura-se a integração entre a prática e os conhecimentos teóricos adquiridos, através de sua aplicação, reflexão, debate e reelaboração". Trata-se de uma etapa indispensável, pois é por meio do estágio que o licenciando vai vivenciar o ambiente escolar, proporcionando a si mesmo a construção de saberes oriundos da própria prática (PELOZO, 2007).

Desse modo, é essencial instigar o licenciando a "aprender fazendo", por meio de dispositivos que estimulem a reflexão sobre o processo formativo em que está inserto e o contexto em que ocorrem as práticas. Essa reflexão - que deve ser provocada pelo professor formador - é fundamental para o futuro professor, pois lhe permite elaborar uma prática capaz de resolver situações decorrentes do processo de ensino e aprendizagem. Assim, o licenciando vai se tornando um professor com senso crítico, capaz de analisar o currículo e desenvolver estratégias educativas no contexto da sala de aula. Diante disso, Monteiro (2002, p. 143) argumenta que "O grande mérito dessa proposta de formação consiste no fato de que ela viabiliza a articulação da teoria com a prática respeitando a subjetividade dos docentes".

Portanto, em sua função de articular a teoria e a prática, o estágio supervisionado costuma estruturar-se em três momentos, que são a observação, a coparticipação e a regência. Esses momentos distintos, mas interconectados, proporcionam ao estudante de licenciatura a inserção na escola, por contribuir para a compreensão do contexto escolar e para a formação da autonomia no desenvolvimento das atividades em sala de aula (MONTEIRO, 2002). Cabe considerar que as etapas conferem ao estudante de licenciatura a construção de conhecimentos profissionais de forma gradativa, o que lhe permite refletir sobre o seu fazer docente e sobre o ambiente escolar em que ele se encontra, além da forma com que os sujeitos integrantes da escola se posicionam em relação ao planejamento escolar e pedagógico.

Neste texto, apresentamos algumas reflexões sobre o estágio supervisionado oriundas de uma investigação que tomou como fonte de dados os relatórios de estágio de futuros professores. Teoricamente, articulamos essas reflexões com as pesquisas sobre os saberes docentes desenvolvidas por Shulman (1986), Tardif (2006) e Gauthier et al. (2006). Acreditamos que esse diálogo traz uma contribuição para os estudos que investem na produção do saber docente durante a formação inicial ou no decorrer dos processos formativos. 
No contexto deste estudo, a Prática de Ensino do curso de licenciatura em Ciências Biológicas da Universidade Estadual do Sudoeste da Bahia (UESB) ocorre por meio dos componentes curriculares relacionados ao estágio supervisionado. Essa fase da formação se configura como uma importante etapa da graduação, uma vez que visa inserir os estudantes/estagiários nas escolas para que, mediante a experiência vivenciada, eles possam conhecer o ambiente de ensino e elaborar dispositivos pedagógicos adequados ao seu trabalho.

Ao final das etapas de observação, coparticipação e regência que compõem o estágio supervisionado, os licenciandos produzem relatórios, que têm como função primordial demonstrar como a Prática de Ensino contribuiu na sua futura atuação profissional. Para o presente trabalho, um total de trinta relatórios produzidos depois da realização do estágio supervisionado de Ciências Biológicas foi utilizado como fontes de dados com o objetivo de compreender as contribuições das disciplinas da Prática de Ensino para a construção dos saberes docentes, sem desconsiderar as dificuldades encontradas pelos estagiários.

Dessa forma, tomamos como aporte metodológico os pressupostos da pesquisa qualitativa no campo da "análise documental" com a qual procuramos articular reflexivamente os depoimentos e os posicionamentos dos sujeitos em estruturas semelhantes ou distintas, identificando os significados atribuídos à produção dos saberes profissionais. Nessa perspectiva, os relatórios foram analisados por meio da Análise de Conteúdo (BARDIN, 1977; MACEDO, 2004) que consistiu em três fases: (a) pré-análise, (b) exploração do material, e (c) tratamento dos resultados obtidos e interpretação.

Na pré-análise foram realizadas leituras das fontes, as quais permitiram a identificação das unidades de registro - palavras, frases ou enunciados-, sem desconsiderar a unidade de contexto em que estas unidades de registro foram produzidas. Esse movimento permitiu identificar aspectos destacados pelos licenciandos durante a Prática de Ensino que demonstravam a relevante contribuição do estágio supervisionado na construção dos saberes profissionais e as principais dificuldades encontradas nas aulas. $\mathrm{Na}$ segunda fase - exploração do material -, foram realizadas sucessivas leituras na tentativa de interpretar os sentidos contidos nos relatos. Na última fase procuramos desvendar o conteúdo subjacente ao que está manifestado por meio da interpretação dos resultados.

Dessa forma, esperamos que os resultados do presente estudo colaborem para o debate sobre a formação inicial e a produção dos saberes 
docentes, pois as reflexões ora apresentadas nos levam a pensar num conjunto de pressupostos que envolvem o estudo das relações entre esses saberes e os conhecimentos escolares na formação de professores.

\section{A PRODUÇÃO DOS SABERES DOCENTES E O ESTÁGIO SUPERVISIONADO}

A Prática de Ensino é um elemento articulador no processo de formação, pois permite que o futuro professor vivencie situações pedagógicas em contextos reais de ensino no espaço escolar. Segundo Santos Filho (2010), devemos considerar que a Prática de Ensino integra o conhecimento construído pelos discentes em sua permanência na academia com a experiência que será adquirida por eles na condição de profissionais nos momentos de sala de aula.

As experiências dos licenciandos no estágio supervisionado promovem transformações gradativas que os fazem oscilar entre "ser aluno" e "ser professor". Monteiro (2002, p. 141) afirma que, nessa etapa, os licenciandos

[...] vivem um momento estratégico em sua vida profissional, vivenciando um ritual de passagem. Ele/ela é, ao mesmo tempo, aluno e professor, portanto tem a sensibilidade aguçada para perceber as repercussões da ação educativa com olhos de quem ainda se sente como aluno.

Dessa forma, "[...] a docência vai se caracterizando como trabalho interativo, o qual contém a singularidade de ser impregnado pelo objeto humano e que, portanto, o trabalho modifica a identidade do trabalhador, na medida em que este vai se formando" (VILELA, 2008, p. 86). Os depoimentos a seguir, extraídos das fontes analisadas, demonstram as singularidades desse momento na trajetória de formação do futuro professor, assim como nos aprendizados da docência.

Ao se aproximarem do seu futuro ambiente de trabalho, os estudantes de licenciatura começam a reconhecer aspectos que serão carregados durante toda a sua vida. Eles aprendem a se portar como professores; conhecem o funcionamento da escola; familiarizam-se com as exigências cotidianas da instituição; aprendem a lidar com dificuldades recorrentes na sala de aula; tornam-se autônomos para tomar decisões e criar atividades que os permitam viabilizar uma maior construção de conhecimentos por parte dos seus alunos e, assim, vai elaborando o seu perfil profissional (Relatório 19).

A experiência prática representa para os estagiários uma real oportunidade de aprendizagem e ação. O"choque da prática" é a ocasião para o estagiário 
se confrontar com a situação de ajustar a aula concreta ao que aprendeu na universidade. Por outro lado, esta experiência facilita a estruturação e a aquisição de competências de ensino graças a um trabalho de interpretação e análise contextualizada (Relatório 2).

Como destacado no Relatório 2, a realidade das aulas faz com que o estagiário perceba - pelo processo de reflexão da sua prática - que os conteúdos aprendidos na universidade necessitam de retradução para serem compreendidos pelos alunos da escola. De acordo com Vilela (2009), no contexto da Prática de Ensino os conhecimentos adquiridos na universidade ganham novos sentidos à medida que, por meio da reflexão, o estagiário começa a mobilizar conteúdos para o ensino, adequando-os às situações em que ele se encontra. Portanto, o licenciando começa de "modo autoral" a produzir saberes profissionais ainda no processo de formação no qual está inserto.

Vilela, Ayres e Selles (2006) afirmam que esse momento da formação é fundamental para o início da profissionalização no magistério, uma vez que permite a constituição de "coletividades docentes". Essas coletividades são construídas ao longo do estágio e se prolongam por toda a atuação docente, o que possibilita a inserção do profissional nos vários ramos da docência.

A princípio, o processo prático de formação ocorre por meio das relações que são produzidas pelos atores que compõem o cotidiano escolar. Em vários relatórios analisados, ficou claro que o momento inicial da Prática de Ensino - a observação - é fundamental para que esse encontro com a realidade de "ser professor" ocorra de forma paulatina e significativa. Vejamos alguns relatos:

A observação é uma etapa muito valiosa durante o estágio, pois é o primeiro contato com a realidade da escola e dos alunos. Através da observação, fazemos nossas críticas e previsões para a regência, analisamos a forma que nos comportaremos perante a turma, a forma como os alunos aprendem melhor os assuntos com os quais eles têm uma maior afinidade e os problemas que ocorrem na sala de aula e na escola. Enfim, é durante a observação que se "constrói" o mundo escolar [compreende o contexto] [...] (Relatório 7).

[...] a etapa de observação é o momento de conhecer os alunos, e, através destes, o professor encontrará meios para a solução de possíveis problemas, podendo desenvolver um excelente trabalho (Relatório 11).

Acredito que as duas primeiras fases (observação e coparticipação) foram essenciais para que eu seguisse para a regência, pois foram nelas que pude entrar na rotina da sala de aula e perceber a problemática que eu iria enfrentar e a partir daí tentar desenvolver um planejamento que me ajudasse a resolver problemas (Relatório 15). 
Como os dados apontam, é na observação que o futuro professor começa a construir sua identidade docente e alguns saberes profissionais. Conforme Almeida (1995), pode-se afirmar, mediante as leituras do material empírico e a identificação dos núcleos de sentido nas narrativas ${ }^{1}$, que essa etapa do estágio se constitui elemento facilitador para os licenciandos, pois é quando muitos deles iniciam sua relação com a turma e, por conseguinte, abrem mão de medos e receios presentes nos primeiros momentos em sala de aula.

Nessa perspectiva, não apenas a observação, mas também as etapas que se seguem - a coparticipação e a regência - foram destacadas nos relatórios analisados. Acerca da coparticipação, a narrativa seguinte ressalta: “[...] a coparticipação tende a proporcionar ao estagiário um contato ímpar com a turma, assim como o período de observação, pois possibilita analisar o contexto e estabelecer as melhores estratégias didáticas a serem trabalhadas" (Relatório 5).

No decorrer da análise, ficou evidente que a regência foi o centro das reflexões apresentadas pelos estagiários em suas narrativas. Almeida (1995) configura a regência como o"coroamento", já que nessa etapa o aluno deixa de ser um participante da aula e passa a ser o idealizador. Portanto, é indiscutível a importância dessa fase do estágio, que se torna a mais longa e a mais ativa e, por isso, a maior fonte de experiências e de produção de saberes profissionais.

O relato de um dos licenciados destaca: "Durante a regência, o estagiário passa a ver a comunidade escolar como um todo. Através das observações já realizadas e das anotações feitas, ele faz uma releitura do ambiente, procurando meios para intervir de maneira positiva" (Relatório 7).

A intervenção mencionada no depoimento anterior vem sempre articulada ao que foi aprendido na universidade durante as aulas teóricas dos componentes curriculares relacionados à Prática de Ensino. Quando se torna"regente" da turma, o estagiário associa os conhecimentos específicos da sua área aos conhecimentos e estratégias pedagógicas da Prática de Ensino, mobilizando saberes docentes oriundos de sua formação profissional e pessoal. Portanto, esses achados dialogam com os estudos de Tardif (2006), que afirma ser o saber docente um saber diverso, composto de vários saberes vindos das instituições formativas, da ação cotidiana, da formação profissional e do currículo.

Outro aspecto relevante presente nos relatos é a importância atribuída ao planejamento da aula como uma estratégia facilitadora do processo de ensino. Segundo Moretto (2007), o ato de planejar permite "organizar as ações". Essa organização favorece o desempenho do professor ao ministrar 
a aula e o aprendizado do aluno, uma vez que permite ao professor a compreensão do que está sendo ensinado. No que se refere ao planejamento, outros depoimentos destacam:

O planejamento constitui-se uma importante ferramenta para o professor, uma vez que permite a elaboração e a escolha da melhor estratégia didática a ser utilizada. [...] o ato de planejar é essencial para que o professor consiga garimpar meios de fornecer aos seus alunos metodologias que assegurem a eles a construção dos seus próprios conhecimentos, bem como aperfeiçoar a pesquisa e a reflexão do professor que a desenvolve (Relatório 9).

[...] é essencial para a organização do conteúdo e serve como apoio para que a aula seja desenvolvida em momentos futuros, assim como para a autoavaliação da metodologia de ensino. [...] Um dos principais desafios encontrados na produção dos planos de aula foi a transformação do conteúdo de ensino superior para o conteúdo de ensino fundamental, de modo que este não estivesse demasiadamente simplificado e também não estivesse além do que se fez necessário para a turma (Relatório 4).

Como apontado no último fragmento, o planejamento torna-se um elemento desafiador ao passo que exige do estagiário a transformação do conteúdo que é aprendido no ensino superior. Esse movimento didático-pedagógico do licenciando indica o modo como ele mobiliza os seus saberes na produção do conhecimento escolar. Sobre o processo de retradução do conteúdo, Shulman (1986, p. 6) argumenta:

[...] as ideias devem ser transformadas para serem ensinadas. Refletir sobre caminho da ideia através de um ato de ensino é refletir a partir da forma com que uma matéria é entendida pelo professor até a forma com que ela se apresentará nas mentes e motivação dos alunos.

Quando o licenciando modifica o conteúdo, adequando-o às necessidades da turma, ele realiza uma ação exclusiva do docente, uma vez que, para que ocorra retradução ou transformação dos conhecimentos científicos/ acadêmicos, é necessário possuir domínio dos conteúdos, além de destreza pedagógica para realizar tais modificações. Nesse movimento de mobilização que ele realiza, ocorre a produção de saber docente. Nessa concepção, Marandino $(2004$, p. 95$)$ defende a ideia de que "[...] a transformação do conhecimento científico com fins de ensino e divulgação não constitui simples 'adaptação' ou mera 'simplificação' de conhecimento, podendo ser então analisada na perspectiva de compreender a produção de novos saberes nesses processos". 
Ainda no tocante à transformação do conteúdo que é aprendido na academia e abordado na escola, Gauthier et al. (2006, p. 30) enfatizam: “[...] uma disciplina nunca é ensinada tal qual, ela sofre inúmeras transformações para se tornar um programa de ensino". Nesse sentido, os autores apontam a necessidade de o educador ter o saber curricular, o qual é imprescindível para auxiliar na adequação dos programas das disciplinas para a turma que atua.

Atrelada à produção de saberes por meio da mediação (transposição) didática (LOPES, 1999), está a produção de saberes oriundos das estratégias de ensino que são criadas para facilitar a abordagem dos conteúdos e a construção dos conhecimentos pelos alunos. Essas estratégias, segundo os relatórios analisados, materializaram-se também por meio dos modelos didáticos já construídos. Assim, a análise mostrou que, durante a realização do estágio, primou-se pela inovação metodológica, o que possibilitou a reelaboração dos conhecimentos da formação profissional, os quais carecem ser pedagogicamente adequados por meio de técnicas e métodos de ensino (TARDIF, 2006). Os depoimentos a seguir mostram de que modo os estagiários mobilizaram os saberes pedagógicos para retraduzir os conhecimentos científicos e acadêmicos:

A execução do projeto de estágio, utilizando materiais didáticos, demonstrou como o uso de metodologias diferenciadas pode auxiliar o trabalho do professor e contribuir com a aprendizagem dos alunos. Além de possibilitar aos estagiários a mobilização do saber científico articulado ao saber pedagógico, ambos essenciais para a formação profissional, uma vez que é somente na ação que o saber e o saber ensinar do professor são postos em prática (Relatório 9, grifo nosso).

Além dos jogos, as várias dinâmicas que podem ser aplicadas em sala, fortalecem e enriquecem as aulas, auxiliando tanto professor, quanto aluno na busca pelo conhecimento (Relatório 8, grifo nosso).

A utilização de novas metodologias e técnicas para explicar os conteúdos e estabelecer uma transversalidade com o cotidiano fez com que a ciência/ biologia ficasse mais próxima da realidade deles (Relatório 5, grifo nosso).

Diante de tais considerações, os saberes que permeiam a docência aparecem de forma implícita. Em muitos relatos, os licenciandos apontam indícios que remetem à compreensão de que há produção dos saberes profissionais durante o estágio supervisionado. Nessa direção, um deles diz que os saberes docentes "[...] não são aprendidos apenas nos cursos de formação inicial, mas podem ser também gerados no cotidiano da prática profissional 
[...]" (Relatório 1). Esse argumento reforça a ideia de que os saberes docentes começam a ser produzidos na formação inicial e se prolongam em a toda carreira do profissional.

Segundo Tardif (2006, p. 36), o saber docente é"[...] um saber plural, formado pelo amálgama, mais ou menos coerente, de saberes oriundos da formação profissional e de saberes disciplinares, curriculares e experienciais". Esses saberes estão intimamente ligados ao trabalho que é desenvolvido no cotidiano, tanto na universidade quanto nas escolas.

Nesse sentido, no fragmento abaixo, o licenciando ressalta a necessidade de vivenciar situações pedagógicas em contextos reais de ensino durante o estágio supervisionado.

A prática de ensino que não oportuniza maior socialização entre pares pode sinalizar para os futuros professores que os saberes acadêmicos possuem maior legitimidade do que os demais saberes relativos à ação docente. Essa hierarquização torna difícil para os futuros professores lidarem com outros processos formativos que se dão em um contato mais profundo com as situações reais do cotidiano da escola (Relatório 1).

O licenciando destaca, pois, o cuidado que se deve ter para não tomarmos como única referência o saber científico e acadêmico. De fato, esse saber se configura como essencial para a atuação profissional, já que é a partir dele que são retraduzidos os conhecimentos que serão abordados na escola. No entanto, existe uma gama de saberes relacionados à prática que não podem ser secundarizados. Defendemos, portanto, a ideia de que o estágio supervisionado, por meio das relações estabelecidas entre os atores no contexto escolar e das situações de ensino que o estagiário vivencia, permite a produção de saberes profissionais, sem os quais o processo de ensino-aprendizagem estaria comprometido.

Corroborando o que foi apresentado, Gauthier et al. (2006, p. 28) argumentam que são mobilizados no ato de ensinar "[...]vários saberes que formam uma espécie de reservatório no qual o professor se abastece para responder a exigências específicas de sua situação concreta de ensino".

Os trechos apresentados a seguir mostram que a Prática de Ensino não é uma mera disciplina inserida no currículo das universidades. Trata-se de um componente curricular de relevância para a licenciatura, na medida em que apresenta aspectos inerentes à carreira docente como o reconhecimento da identidade profissional e da escola como um local de produção de conhecimentos docentes no exercício de ensinar (FORQUIN, 1992). 
Devemos, portanto, considerar que realizar o estágio não é apenas finalizar mais uma disciplina necessária para a conclusão do curso. É formar o saber docente junto aos conhecimentos teóricos que se têm, lembrando que as dificuldades que são encontradas durante todo este processo são enriquecedoras (Relatório 19).

[...] o estágio supervisionado se afirma como momento de construção de saberes docentes, saberes esses que vão além da transmissão dos acadêmicos, pois envolvem o desenvolvimento pessoal e profissional (Relatório 6).

Podemos, diante do exposto, considerar que esse componente curricular é reconhecido pelos licenciandos como uma oportunidade não apenas de conhecer a escola e vivenciar uma nova experiência, mas também como um momento de construir saberes docentes por eles reconhecidos e utilizados.

Em outra perspectiva, o estágio supervisionado permite ao licenciando os primeiros contatos com o ambiente escolar, onde irá conhecer e vivenciar seus problemas. Esse aspecto foi mencionado em muitos relatórios, nos quais o estágio aparece como um período muito difícil, uma vez que obstáculos inerentes ao ensino foram revelados.

Algumas narrativas explicitavam um conjunto de fatores caracterizados por um processo de "indisciplina aprimorada", a qual Garcia (1999) denomina de "bagunça engajada", que é marcada pela alteração das manifestações de indisciplina no meio escolar. Garcia (1999, p. 103) exemplifica essa problemática da seguinte maneira:

[...] ocorre, por exemplo, quando os alunos de uma turma de ensino médio, mesmo formada por grupos divergentes entre si, são capazes de se organizar e estabelecem atitudes indisciplinadas coletivas, que vão desde a prática de um mesmo tipo de tratamento evasivo durante as aulas de determinado professor, passando por estratégias para intimidar uma professora a ponto de forçar que esta abandone a escola, até processos complexos de contestação da orientação pedagógica dos professores e da escola.

Esse tipo de comportamento faz com que o estagiário se sinta inseguro, o que muitas vezes pode ser um agravante no desempenho do trabalho que ele propôs realizar. Tardif (2006) e Cavaco (1995) referem-se a esse momento da graduação (a Prática de Ensino) como um período muito instável, pois é nessa etapa que o estagiário vai construir sua identidade profissional. Trata-se de um momento suscetível à insegurança, que o faz muitas vezes pensar em desistir. 
No relato a seguir, o licenciando sugere uma alternativa, a qual será classificada por ele como eficiente para amenizar a problemática da indisciplina.

O diálogo parece ser o melhor instrumento para lidar com a indisciplina no ambiente escolar. As regras rigorosas, tanto na escola quanto na sala de aula, parecem ter um efeito contrário, aumentando os conflitos. O professor consegue lidar melhor com os problemas de conduta no decorrer dos anos de docência à medida que vai ganhando experiência e conhecimento. Os métodos de ensino pautados na repetição, na punição e no controle excessivo provocam a revolta no estudante, aumentando os conflitos entre professor e aluno (Relatório 2).

Pelo que foi exposto na narrativa anterior, é perceptível que ao tentar solucionar problemas decorrentes do ambiente em que ele se encontra, o professor constrói saberes experienciais, os quais Santos (2010, p. 162, grifo nosso), baseado nos estudos de Tardif, define como "[...] fruto do trabalho cotidiano destes [referindo-se aos professores], brotando assim das suas práticas, sendo nela validados, legitimados". O fragmento analisado traz consigo a constatação da legitimação desses saberes e nele o estagiário propõe uma solução para o problema mediante sua percepção no decorrer do estágio.

Além da indisciplina, outros aspectos foram evidenciados pelos licenciandos. A falta de infraestrutura das escolas foi apontada como um elemento relevante e negativo no momento da atuação dos professores de Ciências e Biologia.

No ensino de biologia, percebem-se dificuldades que são encontradas pelos professores na realização de aulas práticas. Com a indisponibilidade de recursos didáticos necessários para a execução da atividade e laboratório inadequado, a aula prática foi desenvolvida em sala de aula (Relatório 3).

A ausência de espaço físico adequado para realização das atividades práticas e a indisponibilidade de recursos didáticos permitiram que os estagiários conhecessem as estratégias utilizadas pelos professores da escola para desenvolver uma prática pedagógica diferenciada. Tais situações, embora adversas, permitem ao futuro professor conhecer exatamente o contexto da maioria das escolas públicas brasileiras e criar estratégias didático-pedagógicas que possam contornar as dificuldades encontradas no percurso. Entretanto, esses fatores podem se tornar um agravante, pois inviabilizam a realização de atividades significativas e contribuem para o desinteresse dos alunos pelas aulas e dos professores pelo planejamento. 
De acordo com Tardif e Lessard (2009), o professor necessita de condições adequadas para realizar a docência, as quais estão relacionadas aos materiais e à adequação do ambiente ao ensino. Assim, os dados empíricos dialogam com a denúncia de Tardif e Lessard (2009), uma vez que explicitam a imprescindibilidade que o professor tem de lecionar em um ambiente adequado, que favoreça o desenvolvimento das suas aulas e aumente a possibilidade de produção do saber docente e da compreensão dos conteúdos pelos seus alunos.

Acerca das adequações que são exigidas pelo processo de ensino, um dos licenciandos diz que "[...] um dos maiores desafios para a escola e os professores é desenvolver estratégias de ensino que acompanhem o ritmo atual de inovações tecnológicas que o aluno está acostumado" (Relatório 7). Nesse sentido, Bento e Cavalcante (2013) afirmam que os educadores necessitam de adequação ao uso de tecnologias móveis, uma vez que estas já fazem parte do cotidiano dos alunos e podem tornar-se uma aliada no processo de ensino.

Por fim, um dos fragmentos traz um apontamento interessante no que diz respeito às dificuldades enfrentadas durante o estágio:

O estágio tende também a pôr em pauta os desafios da prática na formação inicial, desafios como: resistência ao estagiário e ao aprendizado, comparações com o professor regente, indisciplina, hiperatividade, desmotivação, entre outros. Mas tais desafios presentes na formação inicial servem de subsídios para a nossa constituição profissional [...] (Relatório 5).

Diferentemente do que foi apresentado nos demais relatórios, o fragmento anterior não apenas mostra as dificuldades advindas da Prática de Ensino, mas também destaca o fato de que tudo o que é vivenciado no estágio pode ser visto como uma possibilidade de crescimento profissional. Assim, para Monteiro (2002), a experiência não é oriunda de vivências que podem ser copiadas, mas de novas vivências, nas quais o sujeito seleciona, identifica, focaliza os conhecimentos significativos para a prática profissional e exclui aqueles que não foram aproveitados por sua própria ação.

\section{CONSIDERAÇÕES FINAIS}

Nessa investigação, assumimos o desafio de compreender como o estágio supervisionado pode contribuir para o desenvolvimento profissional dos estudantes de licenciatura. Procuramos analisar a contribuição da Prática 
de Ensino na construção dos saberes docentes, identificando as principais dificuldades encontradas durante a realização das aulas de Ciências e Biologia no decorrer do estágio. Para tanto, tomamos como suporte teórico dessa produção as contribuições de estudos realizados por pesquisadores que discutem a formação docente, a Prática de Ensino e os saberes que estão ligados à profissionalização do ensino, a fim de que, mediante os fragmentos selecionados nos relatórios, pudéssemos prosseguir com a análise e a interpretação dos dados.

Diante disso, os resultados evidenciaram o fato de que as disciplinas de Prática de Ensino são componentes muito importantes para o currículo das licenciaturas, visto que, nessa etapa da graduação, o licenciando, ao inserir no ambiente escolar, reconhece-se como professor, exercitando na prática os conhecimentos disciplinares adquiridos na formação inicial. Vale considerar, portanto, que é neste momento que o graduando legitima a produção de seu próprio saber docente mediante as situações de ensino encontradas no decorrer do estágio supervisionado.

No que se refere aos saberes docentes, podemos considerar que os estagiários perceberam a sua existência e a sua importância para o processo de profissionalização. Ao exercerem a função docente, foram capazes de reconhecer esses saberes intrínsecos à ação dos professores nas escolas. Dessa forma, entenderam que a Prática de Ensino permite a construção dos saberes inerentes ao magistério.

Outros aspectos foram salientados pelos licenciandos ao aportarem as dificuldades encontradas na realização das aulas de Ciências e Biologia. A indisciplina, a falta de infraestrutura e de adaptação das aulas às tecnologias móveis foram as principais dificuldades apontadas. A indisciplina parece ser o maior obstáculo durante as atividades do estágio, sendo atribuído a esse fator o insucesso em algumas aulas e a falta de motivação para desenvolver as atividades propostas.

As constatações mencionadas, embora marcadas pelas adversidades presentes no espaço escolar e na sala de aula, possibilitam afirmar que o estágio supervisionado contribui para o desenvolvimento profissional dos estudantes de licenciatura, pois Ihes permite vivenciar suas primeiras tentativas de construção dos saberes docentes em situações de ensino mediadas por reflexões advindas da formação inicial. A Prática de Ensino, portanto, representa um momento acadêmico cheio de possibilidades, uma vez que o licenciando conclui um ciclo na formação e inicia um processo de inserção no espaço profissional. 


\section{PRODUCTION OF TEACHERS' KNOWLEDGE AND SUPERVISED INTERNSHIP: WHAT THE STUDENTS' NARRATIVES SAY}

ABSTRACT: This research focused on the knowledge produced by graduates in Licenciatura in Biology during the supervised internship. By using internship narratives as data source, this research examined in particular the contributions from the disciplines of Teaching Practice for the development of teachers' knowledge, without disregarding the difficulties students encountered. The results point to the fact that the insertion of the graduate in actual teaching situations at school allows the retranslation of the knowledge acquired in the initial training. Therefore, internship activities contribute to the professional development of undergraduate students as they allow them to experience, supported by reflections arising from their training, their first attempts of teachers' knowledge construction in educational contexts.

KEYWORDS: Supervised internship. Teacher education. Teaching practice. Teachers' knowledge.

\section{LA PRODUCCIÓN DE LOS SABERES DOCENTES Y LA PRÁCTICA SUPERVISADA: LO QUE DICEN LAS NARRACIONES DE LOS ALUMNOS}

ResUmen: Esta investigación se centró en los saberes producidos por licenciados en Ciencias Biológicas durante la práctica supervisada. Al utilizar los informes de la práctica como fuente de datos, esta investigación examinó las contribuciones de las asignaturas Práctica de la Enseñanza para la construcción de los saberes docentes, sin dejar de lado las dificultades encontradas por los practicantes. Los resultados indican que la inserción del licenciado en situaciones reales de enseñanza en la escuela permite hacer una retraducción de los conocimientos adquiridos en la formación inicial. Por lo tanto, las actividades de la práctica docente contribuyen con el desarrollo profesional de los estudiantes de licenciatura, porque les permite vivir sus primeros intentos de construir saberes docentes en los contextos de enseñanza con el apoyo de reflexiones provenientes de su formación.

Palabras-clave: Práctica supervisada. Formación de profesores. Práctica de la Enseñanza. Saberes docentes. 


\section{NOTAS}

1) O termo "narrativa" é empregado neste estudo no sentido amplo e não no sentido historiográfico.

\section{REFERÊNCIAS}

ALVES, W. F. A formação de professores e as teorias do saber docente: contextos, dúvidas e desafios. Educação e Pesquisa, São Paulo, v. 33, n. 2, p. 263-280, 2007.

ALMEIDA, J. S. Prática de ensino e estágio supervisionado na formação de professores. Cad. Pesq., São Paulo, n. 93, p. 22-31, 1995.

BARDIN, L. Análise de conteúdo. Lisboa: Edições 70, 1977.

BENTO, M. C. M.; CAVALCANTE, R. S. Tecnologias Móveis em Educação: o uso do celular na sala de aula. ECCOM, São Paulo, v. 4, n. 7, p. 113-120, jan./jun. 2013.

CAMPOS, L. M. L.; DINIZ, R. E. S. A prática como fonte de aprendizagem e o saber da experiência: o que dizem os professores de Ciências e Biologia. Investigações em Ensino de Ciências, Porto Alegre, v. 6, n. 1, p. 79-96, 2001.

CAVACO, M. H. Ofício de professor: o tempo e as mudanças. In: NÓVOA, A. (Org.). Profissão Professor. Portugal: Porto, 1995. p. 155-191.

FAGUNDES, L. S.; PAZ, D. M. T. Importância do Estágio Supervisionado em Ciências e Biologia para complementar a formação do licenciado. In: Seminário Interinstitucional de Ensino, Pesquisa e Extensão, 17; Mostra de Iniciação Científica, 15, e Mostra de Extensão, 10, 2012, Cruz Alta. Anais... Cruz Alta: UNICRUZ, 2012.

FORQUIN, J. C. Saberes escolares, imperativos didáticos e dinâmicas sociais. Teoria \& Educação: discurso pedagógico, cultura e poder, Porto Alegre, n. 5, p. 28-49, 1992.

FRANCO, M. A. S. Entre a lógica da formação e a lógica das práticas: a mediação dos saberes pedagógicos. Educação e Pesquisa. São Paulo, v. 34, n. 1, p. 109-126, jan./abr. 2008.

GABARDO, C. V.; HOBOLD, M. S. Início da Docência: Investigando professores do Ensino Fundamental. Revista Brasileira de Pesquisa sobre Formação Docente. Belo Horizonte, v. 3, n. 5, p. 85-97, ago./dez. 2011.

GARCIA, J. Indisciplina na escola: uma reflexão sobre a dimensão preventiva. $R$. Paran. Desenv., Curitiba, n. 95, p. 101-108, jan./abr. 1999.

GAUTHIER, C. et al. Por uma teoria da pedagogia: pesquisas contemporâneas sobre o saber docente. 2 ed. ljuí-RS: Unijuí, 2006.

LOPES, A. C. Conhecimento escolar: ciência e cotidiano. Rio de Janeiro: EDUERJ, 1999. 
MACEDO, R. S. A Etnopesquisa Crítica e Multireferencial nas Ciências Humanas e na Educação. 2 ed. Salvador: EDUFBA, 2004.

MARANDINO, M. Transposição ou recontextualização? Sobre a produção de saberes na educação em museus de ciências. Revista Brasileira de Educação. Rio de Janeiro, n. 26, p. 95-108, maio/ago. 2004.

MONTEIRO, A. M. A prática de ensino e a produção de saberes na escola. In: CANDAU, V. M. (Org.). Didática, currículo e saberes escolares. 2. ed. Rio de Janeiro: DP\&A, 2002. p. 129-147.

MORETTO, V. P. Planejamento: planejando a educação para o desenvolvimento de competências. Petrópolis-RJ: Vozes, 2007.

PELOZO, R. C. B. Prática de Ensino e o Estágio Supervisionado enquanto mediação entre ensino, pesquisa e extensão. Revista Científica Eletrônica de Pedagogia, Garça-SP, ano V, n. 10, p. 1-7, 2007.

SANTOS FILHO, A. P. O Estágio Supervisionado e sua importância na formação docente. Revista Virtual P@rtes, v. 1, São Paulo, 2010. Disponível em: <http://www.partes.com.br/educacao/estagiosupervisionado.asp>. Acesso em: 15 jan. 2014.

SANTOS, J. J. R. Saberes profissionais: uma incursão conceitual. In: CRUSOÉ. N. M. C.; RIBEIRO, M. M. G.; SILVA, C. A.(Org.). Desafios Educacionais no cotidiano da Escola. Ijuí-RS: Ed. Unijuí, 2010. p. 155-180.

SHULMAN, L. Knowledge and teaching: foundations of the New Reform. Harvard Educational Review, v. 57, n. 1, p. 1-22, 1986.

TARDIF, M. Saberes docentes e formação profissional. 7 ed. Petrópolis-RJ: Vozes, 2006.

.; LESSARD, C. O trabalho docente: elementos para uma teoria da docência como profissão de interações humanas. Tradução de João Batista Kreuch. 5 ed. Petrópolis-RJ: Vozes, 2009.

VILELA, M. L. A Biologia na sala de aula pelas escritas de professores em formação: um olhar de pesquisa sobre relatórios de prática de ensino. In: MARANDINO, M. et al. (Org.). Ensino de Biologia: histórias, saberes e práticas formativas. Uberlândia-MG: EDUFU, 2009. p. 89-105.

Dimensões formativas em confronto na prática de ensino escolar: uma investigação de percursos de licenciandos das ciências biológicas. 2008. 258 f. Tese (Doutorado em Educação) - Faculdade de Educação da Universidade Federal Fluminense, Niterói-RJ, 2008.

; AYRES, A. C. M.; SELLES, S. E. A constituição das coletividades docentes como possibilidade formativa na prática de Ensino de Ciências Biológicas. In: Encontro Nacional de Didática e Prática de Ensino, 3, 2006, Recife. Anais... Recife: UFPE, 2006. 
Edinaldo Mederos Carmo: Doutor em Educação pela Universidade Federal Fluminense. Professor Adjunto do Departamento de Ciências Naturais e do Programa de Pós-Graduação em Educação da Universidade Estadual do Sudoeste da Bahia. Atua na área de formação de professores de Ciências e Biologia.

E-mail:medeirosed@uesb.edu.br

WINNE Katharine SouzA RoCHA: Graduanda em Ciências Biológicas pela Universidade Estadual do Sudoeste da Bahia. Aluna Bolsista do PIBID - Programa Institucional de Bolsa de Iniciação à Docência, no período de 2012 a 2015. Pesquisadora Voluntária de Iniciação Científica no projeto "Produção dos saberes docentes e do conhecimento escolar na formação inicial de professores de Ciências e Biologia". Participante do grupo de pesquisa "Currículo e formação docente". E-mail: nine.wika@hotmail.com 